Supplement of Earth Surf. Dynam., 4, 773-780, 2016

http://www.earth-surf-dynam.net/4/773/2016/

doi:10.5194/esurf-4-773-2016-supplement

(C) Author(s) 2016. CC Attribution 3.0 License.

(c) (i)

Supplement of

\title{
Long-term coastal openness variation and its impact on sediment grain-size distribution: a case study from the Baltic Sea
}

Wenxin Ning et al.

Correspondence to: Wenxin Ning (wenxin.ning@geol.lu.se)

The copyright of individual parts of the supplement might differ from the CC-BY 3.0 licence. 


\section{S1. Python code for generating radiating lines}

The code below was used for generating radial lines in this study. The variables in bold and italic require users' inputs. import arcpy.

from math import radians, sin, cos

output = "FileName.shp" \# Put the name for the file of radiating lines

\# Type the full_path in the first inputs

arcpy.CreateFeatureclass_management("full_path", output, "Polyline")

\# Type the full pathl|File_name.shp here.

cur $=$ arcpy.InsertCursor("full_path\FileName.shp")

\# Type starting $(\Theta)$ and ending angle $(\Phi)$ of the radiating lines in the first two inputs

\# Type radiating lines intervals $(\Delta)$ in the third input

angle_range $=\operatorname{range}(\boldsymbol{\Theta}, \boldsymbol{\Phi}, \boldsymbol{\Delta})$

\# Type the center point coordinate systems (center_x,center_y)

origin_x, origin_y $=\left(\right.$ center_x $\left.\boldsymbol{x}, \boldsymbol{c e n t e r} \_\boldsymbol{y}\right)$

\# Type the radius in meter (r)

distance $=\boldsymbol{r}$

\# Type the degree of half interval here

angle $=\Delta / 2$

for angle in angle_range:

\# start point

lineArray $=$ arcpy.Array ()

start $=\operatorname{arcpy}$.Point ()

$(\operatorname{start.ID}$, start.X, start.Y $)=(1$, origin_x, origin_y $)$

lineArray.add(start)

\# end point

$($ disp_x, disp_y $)=($ distance $* \sin ($ radians $($ angle $))$,distance $* \cos ($ radians $($ angle $)))$

$($ end_x, end_y $)=\left(\right.$ origin_ $\mathrm{x}+\operatorname{disp} \_\mathrm{x}$, origin_y + disp_y $)$

end $=\operatorname{arcpy}$.Point ()

$($ end.ID, end.X, end.Y $)=(2$, end_x, end_y $)$

lineArray.add(end)

feat $=$ cur.newRow ()

feat.shape $=$ lineArray

cur.insertRow(feat) 
del feat, lineArray

else:

print '\%d' \%(angle)

del cur 